\title{
Gringo iracundo: Roque Dalton y su padre
}

ROGER ATWOOD

Traducción: Werner Matias Romero y Roger Atwood

Resumen: Roque Dalton escribió en muchas oportunidades sobre su padre, el estadounidense Winnall Dalton, y su migración a El Salvador. A través de la figura del padre, Dalton desarrolló sus ideas sobre la opresión, la identidad y la relación entre los excluidos y los poderosos. En este artículo el autor se refiere a la manera en que la representación que Dalton dio de su padre reflejó la evolución de sus ideas sobre el imperialismo y el ejercicio del poder a nivel personal y político. Se propone aquí una nueva perspectiva sobre la relación de Dalton con su padre sobre la base de datos biográficos inéditos.

Abstract: Roque Dalton wrote in several occasions about his father, the American citizen Winnal Dalton and his migration to El Salvador. Through his image, Dalton developed his ideas on oppression, identity and the relation between the excluded and the powerful. In this essay, the author refers the way in which Dalton represented his father reflects the evolution on his ideas on imperialism and on the exercise of power. A new perspective on the relation of Dalton with his father is proposed here, based on inedited biographical data.

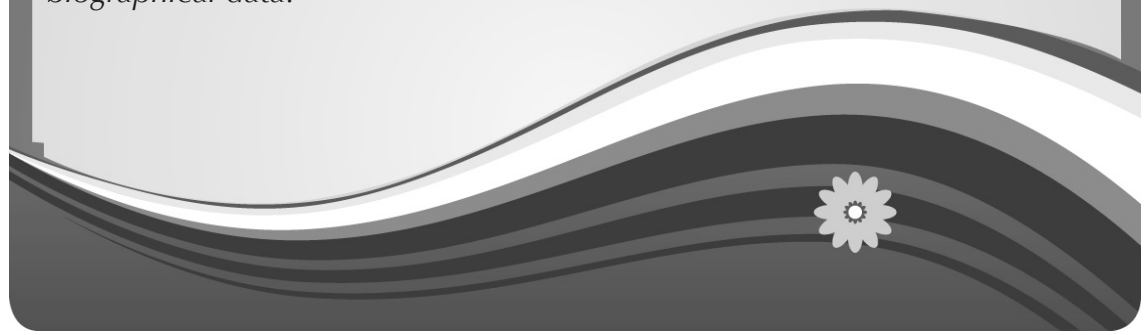

$\mathrm{R}$ oque Dalton -poeta, periodista, ensayista y legendaria estrella fugaz de la literatura- escribió en muchas oportunidades sobre su padre, el estadounidense Winnall Dalton, y su migración a El Salvador. A través de la figura del padre y una imagen de él que fue evolucionando de la de un patriarca distante y acomodado a una de vaquero de caricatura, Dalton desarrolló sus ideas sobre la opresión, la identidad y la relación entre los excluidos y los poderosos. Con frecuencia, el padre encarnó la férrea jerarquía de clases que Dal- 
ton y otros escritores de su generación intentaron denunciar y derrumbar con su crítica revolucionaria de la sociedad salvadoreña. Con esta representación de su padre, más sutil y matizada de lo que a primera lectura se reconoce, Dalton logró así conectar lo personal con lo político de una manera poco usual para los escritores latinoamericanos de ese entonces.

La presencia dominante del padre fue uno de los elementos autobiográficos en la obra de Roque Dalton del cual intentó hacer sentido y humor casi hasta el día de su muerte a los 39 años en 1975. Dalton nunca se posó en una sola imagen de su padre. Ésta pasó por distintas representaciones contradictorias a lo largo de su carrera, las cuales reflejaron a su vez las contradicciones de sus sentimientos hacia su progenitor en diferentes momentos de su vida. Fue sobre todo después de la muerte de Dalton que la imagen de su padre se transformó en la del amenazante pistolero violento del Far West americano que ha sido adoptado por los autores de varios libros y ensayos y por lo menos una película sobre el poeta. La noción de que Dalton viene de una pandilla de ladrones de bancos fronterizos ha sido ampliamente difundida y ha llegado a ser, en verdad, una parte arraigada de la reputación del poeta.

En este artículo, intento demostrar, primero, que la ascendencia de
Dalton de bandidos norteamericanos es pura ficción y que el padre de Dalton, por el contrario, provino de una convencional familia mexicano-estadounidense prominente en la vida cívica y cultural de la ciudad de Tucson (Arizona). El hecho de que Dalton promovió esta leyenda en los últimos años de su vida no la hace menos fantasiosa. En segundo lugar, intento demostrar que el padre de Dalton efectivamente llegó a tener cierta reputación de pistolero, pero sólo mucho después de haber abandonado el mundo de respetabilidad burguesa en que se crio en Tucson y luego de haberse establecido en El Salvador. A lo largo del artículo, me refiero a la manera en que la representación que Dalton dio de su padre reflejó la evolución de sus ideas sobre el imperialismo $y$ el ejercicio del poder a nivel personal y político. Propongo, por tanto, una nueva perspectiva sobre la relación de Dalton con su padre sobre la base de datos biográficos inéditos que, a su vez, abren una nueva lectura de algunas de sus obras más insignes.

La naturaleza escurridiza de la identidad y el desdibujo intencional de la frontera entre la realidad y el mito en la construcción de Dalton de su propia historia personal han sido temas permanentes de la literatura crítica sobre su obra. Rafael Lara Martínez sostiene que la prosa de Dalton "deriva de la necesidad del escritor por ficcionalizarse $y$ volverse personaje novelesco. Ro- 
que Dalton reinventa su pasado el 'recordar', años después de haber declarado el olvido, detalles significantes, nimios de su encierro". ${ }^{1}$ Sus intérpretes han mirado con escepticismo muchos de los acontecimientos que se le atribuyen a Dalton tanto en la literatura académica como popular, e inclusive en su propia obra literaria, como por ejemplo su milagrosa fuga de la cárcel de Cojutepeque en 1964. ${ }^{2}$ La historia de su linaje de bandoleros se ha repetido sin evidencia alguna, pero con ella, como dice Miguel Huezo Mixco, "Dalton se construyó una aureola de pendenciero que lo seguiría hasta el fin de sus días". ${ }^{3}$

Este artículo se fundamenta en parte en una investigación sobre la vida de Winnall Dalton (1894-1962) realizada en los archivos de la $\mathrm{Bi}$ blioteca del Estado de Arizona, la Sociedad Histórica de Arizona y la biblioteca de la Universidad de Arizona en Tucson, así como en el archivo del Museo de la Palabra y la Imagen y los archivos de la familia Dalton en San Salvador, además de entrevistas con amigos y familiares del poeta, entre ellos su viuda, sus dos hijos que aún viven y el único hijo sobreviviente que se conoce de Winnall Dalton.

El poeta Roque Dalton fue una figura clave en la avant-garde cultural que se formó en El Salvador en los años 50 con un grupo de escritores y artistas conocidos COlectivamente como la Generación
Comprometida. Las tendencias políticas de esta colectividad variaban desde la centro-izquierda hasta el marxismo, pero sus miembros compartieron una idea crítica del orden establecido y un deseo de modernizar los modos de expresión cultural y social en El Salvador y de romper con sus tradiciones opresivas. Liderado por Dalton, el novelista Manlio Argueta, el ensayista Ítalo López Vallecillos (a quien se le atribuye la acuñación del nombre "generación comprometida") y el dramaturgo Álvaro Menéndez Leal, entre otros, el grupo desarrolló una visión cruda e impávida del pasado salvadoreño que rechazaba la idea convencional de una amalgama dichosa de lo indígena y lo hispano para plantear en cambio una historia de violencia de clases, exclusión y mediocridad de élites. ${ }^{4}$ Luego de estudiar derecho en Chile y El Salvador, Dalton trabajó como reportero de noticias y editor literario en San Salvador hasta comienzos de los años 60. Fue detenido por lo menos cuatro veces por su actividad política. Olas sucesivas de represión política lo obligaron a exiliarse en México y Cuba de 1961 a 1964, en Checoslovaquia de 1965 a 1968 y finalmente en Cuba de 1968 a 1973. Sus primeros esbozos poéticos, publicados cuando tenía alrededor de 20 años, tienen un tono declamatorio y algo romántico que recuerda a Neruda, pero muy pronto Dalton logra una extraordinaria claridad y originalidad en su lenguaje. ${ }^{5}$ Innovador continuo, nunca se conformó con componer sólo 
poesía y escribió uno de los textos seminales del testimonial latinoamericano, Miguel Mármol, además de dos historias populares de su país al estilo "collage" bajo la influencia de su amigo el uruguayo Eduardo Galeano. Aunque comunista devoto, se desencantó profundamente con la inercia burocrática y el cinismo que había presenciado en los países del bloque soviético, y al mismo tiempo abandonó, al igual que muchos intelectuales de su generación, la posibilidad del cambio pacífico en su país de nacimiento. ${ }^{6}$ Volvió a El Salvador para plegarse a su incipiente lucha armada en diciembre de 1973 y murió dieciocho meses después a manos de sus propios camaradas en una despiadada lucha interna en el seno de un grupo guerrillero urbano.

La idea de que Roque Dalton, poeta precoz y guerrillero desventurado, tuvo como padre el vástago de una familia de delincuentes rurales norteamericanos, y concretamente un clan de infames ladrones de bancos de Kansas conocidos como los hermanos Dalton, ha calado hondo en los recuentos de su vida. Algunos escritores lo han presentado con un escepticismo debido, otros no. Julio Cortázar, en un elogio a su amigo Dalton, escribió que "ninguno de sus amigos olvidará las historias acaso míticas de sus antepasados, la visión prodigiosa del pirata Dalton, las aventuras de los miembros de su familia." ${ }^{77}$ Galeano relata cómo Dalton le contaba "las hazañas de los famosos hermanos Dalton, pistoleros de película, que habían sido sus antepasados" ${ }^{8}$ En El Salvador muchos escritores han contado la historia de la vida delictiva de los Dalton en Kansas, a veces con lujo de detalle. Por ejemplo, Armando Solís nos cuenta que "la prolífica familia Dalton nació en el Estado de Kansas, y los cuatro hermanos que más tarde dedicarían sus afanes a despojar bienes a sus semejantes, encontraron trabajo como representantes de la ley. Esta dualidad de cuidadores del orden y bandidos, se dio con profusión a lo largo de la historia de la conquista de Far West". ${ }^{9}$

Sea lo que sea la historia del Oeste, la relación de Roque Dalton con los hermanos Dalton de Kansas es pura ficción. No tienen parentesco alguno. El padre de Roque Dalton, Winnall Dalton, Jr., (o Winnall Dalton Vásquez, como a veces se refería) nació en Tucson en 1894. Su padre, Winnall A. Dalton, fue un próspero herrero y fabricante de carruajes de caballos, hijo mayor de un empresario británico en el negocio del transporte marítimo, Henry Dalton, quien había emigrado al Perú, donde ejerció funciones de agente consular británico, para luego trasladarse en 1843 a Los Ángeles cuando esta ciudad todavía era parte de México y pocos años antes de la guerra de Estados Unidos a México (la Guerra del 47). Henry Dalton fue ciudadano británico (no irlandés, francés o austríaco como 
se ha afirmado) y evidentemente muy exitoso en sus negocios ya que compró una enorme extensión de tierra - uno de sus descendientes la describió como de 70 millas cuadradas - en lo que es ahora el este del condado de Los Ángeles. Dalton perdió el título a sus terrenos durante la guerra por razones no enteramente claras; las versiones de la época son contradictorias. Lo que sí está claro es que luego del conflicto, las nuevas autoridades estadounidenses no reconocieron su propiedad, e impotentemente vio a invasores ilegales ocupar sus tierras. Dalton libró una larga batalla contra los gobiernos de ambos países pero no recibió casi ninguna compensación por la pérdida. En 1915, en un relato inédito de la vida de Henry Dalton, su hijo escribió que su padre "perdió sus vastas haciendas, a través de las deudas incurridas en defensa de sus propiedad contra una horda de ocupantes ilegales después de casi treinta años de litigio".$^{10}$ Henry Dalton murió en la pobreza en 1884, siendo aún ciudadano británico. Todavía hasta 1937, la familia Dalton escribía cartas y artículos de prensa protestando contra lo que ellos consideraban como la confiscación injusta de sus tierras en la Guerra de Estados Unidos a México. ${ }^{11}$

Así, la vida de los Dalton en los Estados Unidos comenzó con una queja profunda, que duró por múltiples generaciones, contra el gobierno de ese país por su ex- pansionismo en México. Según sus descendientes, los norteamericanos sospechaban que Henry Dalton simpatizaba con la parte mexicana en la guerra y por eso se opusieron a pagarle una indemnización. ${ }^{12}$ De hecho, Henry Dalton ciertamente obtuvo una pequeña compensación del gobierno mexicano en un caso relacionado a otras tierras en el norte de México, según un documento de 1915 redactado por su hijo que describe pormenorizadamente los términos del arreglo. ${ }^{13}$

El reclamo de Henry Dalton por sus tierras fue el primero de muchas batallas legales, generalmente por derechos de propiedad, que los Dalton libraron en los tribunales de California y Arizona. Fueron al parecer un clan de litigiosos, a diferencia de la imagen de delincuentes. Todos estas rencillas legales, ocurridas mientras Arizona iba perdiendo su carácter fronterizo e iba conformando sus sistemas legales y políticos a las normas estadounidenses, tienen que haber afectado las finanzas personales de Winnall Dalton padre y probablemente contribuyeron a su decadencia en la sociedad de Tucson. Esto puede inclusive haber contribuido a la migración de su hijo del mismo nombre a El Salvador.

Para 1890, Winnall Dalton padre había vendido su capital en la fábrica de carruajes a un amigo de la familia que se llamaba Fred Ronstadt y se embarcó en una serie de 
inversiones agrícolas de poco éxito, seguidas por una desastrosa inversión minera en el norte de México en la cual se decía que perdió unos $\$ 20,000 .^{14}$ Su suerte contrastaba con la de Ronstadt, quien se adaptó al cambio y convirtió el negocio que le había comprado a Dalton en una exitosa ferretería y distribuidora de automóviles, la primera en Tucson. Ronstadt, quien nació en México y era hijo de un inmigrante alemán, era un empresario astuto y prominente líder de una banda de música quien se esforzó por enriquecer la vida cultural de Tucson y fue patriarca de una larga lista de personalidades en las artes. Años después, Ronstadt escribió un recuerdo cálido de su cuñado y socio Winnall Dalton padre, calificándole como un "excelente ejemplo de hombría" cuyo dominio del idioma español era "puro, sin rasgo alguno de acento" ${ }^{15}$

Los Ronstadt y los Dalton fueron extremadamente cercanos y se unieron a través del matrimonio al menos en tres ocasiones. La segunda esposa de Fred Ronstadt fue Lupe Dalton, hija de Winnall Dalton padre y su esposa, la mexicana María Jesús Vásquez. A pesar del toque anglo de sus apellidos, ambas familias fueron consideradas parte de la élite de sangre mexicana de Tucson y se apasionaron por preservar sus tradiciones mexicanas. ${ }^{16}$ Familias prominentes y entrelazadas por el matrimonio como los Dalton y los Ronstadt "admiraban el progreso tecnológico de los Estados Unidos. Sin embargo, muchos de ellos detestaban los aspectos más vulgares y materialistas de la sociedad y cultura estadounidenses", escribe el historiador Thomas Sheridan. "Se sintieron además profundamente perturbados por la creciente discriminación contra los mexicanos en el sudoeste. Sobre todo, estos individuos influyentes se esforzaban por fomentar un sentido de identidad mexicana en las ciudades como Tucson, en aras de ofrecer a los mexicanos que ahí vivían una alternativa a la subordinación o asimilación en los Estados Unidos."17

Esta historia de identidad binacional en la frontera es importante para entender a Winnall Dalton, Jr., el padre de Roque Dalton, ya que indica que, cuando se fue de Tucson con destino a México y luego Centroamérica, era considerablemente menos extranjero de lo que la imagen de un rudo bandido norteamericano nos llevaría a pensar. Aunque ciudadano estadounidense, Dalton fue hijo de madre mexicana y criado en una casa donde tanto él como sus padres hablaban el español fluidamente, y provenía de una ciudad donde fue considerado mexicano. Ambos lados de su familia habían vivido en carne propia la pérdida de territorio mexicano al país del norte y por ello, al menos del lado del padre, guardaban un rencor profundo y personal hacia el gobierno de los Estados Unidos. 
En la medida que los Ronstadt iban subiendo en riqueza y prominencia en la sociedad tucsonense, los Dalton decaían. Winnall Dalton padre tuvo tan mala suerte en sus negocios agrícolas y mineros que se vio obligado a rogarle a su yerno Fred Ronstadt para que le diera un trabajo en la ferretería donde el propio Dalton había sido antes copropietario. ${ }^{18}$ En 1913, primero año completo de Arizona como estado de la unión, Dalton aparece en el Directorio de la ciudad de Tucson como fabricante de carruajes de caballos, profesión que rápidamente se extinguía con la llegada masiva de automóviles a la ciudad. ${ }^{19} \mathrm{El}$ próximo año aparece en la misma publicación como carpintero en el negocio de Ronstadt. Murió en 1917 a la edad de 67 años, de gastritis aguda según su registro de defunción. ${ }^{20}$

Todo esto nos sugiere que el joven Winnall Dalton tuvo buenos motivos para despedirse de Tucson. Su padre, amargado hasta el final de sus días por la pérdida de la hacienda familiar en la guerra con México, como se puede leer en una serie de cartas que escribió en sus últimos años, había perdido un negocio exitoso para después verse reducido a la condición de empleado de tienda. ${ }^{21} \mathrm{Al}$ parecer, el joven Winnall era un hombre impetuoso e inquieto que, desde muy temprana edad, quería escapar de la rutinaria y aburrida sociedad tucsonense. En 1912, a los 18 años, trabajaba como oficinista en el ferrocarril. ${ }^{22}$ $\mathrm{Ni}$ él ni su padre tenían antecedentes delictivos algunos, como lo revelan los archivos policiales del estado. El joven Winnall fundó una empresa de crianza de ganado en los alrededores de Tucson junto con su hermana mayor Hortense y su marido Pepe Ronstadt. El negoció fracasó y por ello sus socios culparon a Winnall. ${ }^{23}$ Los detalles se han perdido, pero queda claro que esta experiencia contribuyó al permanente distanciamiento de Winnall con Tucson, de la cual se fue alrededor de 1916 y a donde aparentemente nunca regresó. Al parecer tampoco lo echaron de menos; su nombre brilla por su ausencia casi por completo en las resmas de cartas, documentos, fotos y otros materiales que los Dalton y los Ronstadt acumularon a lo largo de décadas. Se fue primero a México, en ese entonces en plena Revolución, pero no tardó mucho en llegar a Centroamérica.

El primer rastro que tenemos de Winnall Dalton en Centroamérica data de 17 de julio de 1917. La evidencia es una tarjeta de registro para el reclutamiento militar en la Primera Guerra Mundial, en la cual Dalton, de veintitrés años, se inscribe como minero independiente en el Departamento del Yoro, Honduras. La tarjeta lleva las firmas de Dalton y un agente consular norteamericano. Bajo "servicio militar anterior", el inmigrante estadounidense indica que prestó servicios 
durante un año en la división de caballería del ejército mexicano de Venustiano Carranza. No necesariamente tenemos que creer ciegamente esta aseveración del joven Winnall, pese a que la hizo ante un testigo en un documento oficial jurado. Sin embargo, no es la única evidencia de que Dalton participó en el conflicto mexicano. Tanto él como su hermano mayor Henry (quien se quedó en Tucson y fue posteriormente elegido al Concejo Municipal) enviaron pequeños aviones desde Estados Unidos al ejército de México, en ese entonces bajo el mando de Carranza, según el hijo de Winnall. ${ }^{24}$

El vínculo de Winnall con el ejército de Carranza podría explicar, en parte, una de las leyendas más duraderas sobre Roque Dalton, la cual cuenta que su padre y dos tíos enviaron armas de contrabando a Pancho Villa durante la Revolución Mexicana para después estafarle con una cuantiosa suma de dinero. En su novela autobiográfica póstuma Pobrecito poeta que era yo, el narrador dice:

Así habrá muerto Panchito Villa, plomo sobre plomo, vaya, compadre, ái [sic] le va el otro talegazo, y no sólo él, sino uno que otro de mis desesperados tíos que le robaron la plata de las armas, peso sobre peso; para no decir nada de mi papá ya que un hijo no debe juzgar las acciones de sus jefes, y se las pelaron, diez mil brocas en la bolsa de cada quien, en menos que canta un gallo de Chihuahua. ${ }^{25}$

Este pasaje aparece en medio de un enmarañado monólogo interior de cincuenta páginas, narrado por el personaje Roberto del Monte, alter ego del propio Dalton, mientras espera el comienzo de una conferencia de prensa más o menos en el año 1960. ¿Quién va a hablar en la conferencia de prensa? Nunca sabemos, pero la imaginación del propio periodista-escritor viene a ser la voz principal a la vez que cavila sobre temas que van desde Frank Sinatra a W. B. Yeats y sobre si debería beber menos para ser un mejor comunista. Las voces de personas en su entorno entran y salen, pero la acción central del capítulo son las deambulaciones mentales del propio narrador, una figura pública al igual que Dalton (periodista del Teleperiódico en ese entonces), quien irónicamente tiene otra vida clandestina, la de un activista político de izquierda.

Este pasaje, por lo tanto, nos abre una ventana para entender cómo el propio Dalton hubiera visto y contado el tema de su parentela a otra gente, inclusive a los otros periodistas quienes esperan con él a que comience la conferencia de prensa. Este fragmento también su- 
giere que él veía a su padre como un gangster intrépido y audaz, un delincuente que no se sintió intimidado por el general de la División del Norte, famoso por ser violento, y pudo engañarlo y escaparse con $\$ 10,000$ en el bolsillo. Al referirse a figuras como John Wayne y Gregory Peck, este apartado le da asimismo a la vida de Winnall Dalton una cierta calidad cinematográfica.

Dalton se refirió nuevamente a la supuesta relación de su padre con Pancho Villa en la obra "Dalton y Cía.", la cual traspasa la frontera entre la novela y el ensayo y de la que se publicó un fragmento en la revista Cultura en 2005. En este relato, que data de finales de su última y más larga estadía en Cuba, de 1968 a 1973, Dalton escribe que su padre y hermanos mayores Frank y Garand venden de contrabando rifles Springfield y Remington, revólveres Colt y miles de balas a Villa hasta que los hermanos engañan al general mexicano y huyen con $\$ 30,000$ hacia el sur. Winnall y Frank (luego de que Garand se va por su propio camino) viajan por lúgubres pueblos mexicanos y cantinas estruendosas para mantenerse un paso más adelante de los secuaces de Villa. Frank, dice el relato, pega con la fuerza de una patada de burro, mientras Winnall sabe reventar focos eléctricos de un solo balazo cuando repentinamente necesita de un ambiente oscuro. Son el prototipo del estadounidense odioso (ugly American). No pagan sus cuentas, seducen a inocentes doncellas (cuyos padres después vienen corriendo tras los viajeros con escopeta en mano) y dan golpizas tan fuertes a sus rivales que los dejan irreconocibles. Tienen, no obstante, un lado más circunspecto. Los dos hermanos saben recitar a sonetos de Shakespeare, aunque no los entienden del todo, y saben "que la vida sin una tendencia ordenadora es un contrasentido" 26 - que, en el caso de ellos, es engañar y aprovecharse de todos a su alrededor. Van hacia el sur hasta Chiapas y cruzan sigilosamente la frontera hacia Guatemala, donde entablan una amistad con el futuro dictador Jorge Ubico.

Es difícil saber si Dalton quiso que este colorido relato se interpretara como verdad literal, que, pese a su contenido picaresco, está escrito de un estilo mayormente opaco y enredado. Lo escribió en largas sesiones nocturnas en un momento muy difícil en su vida, en 1973, cuando estaba recién divorciado, había roto sus relaciones con Casa de las Américas por un conflicto personal con su director Roberto Retamar Fernández, y estaba a pocos meses de volver a El Salvador para su mal augurada temporada con el incipiente movimiento guerrillero. Estaba tomando "más de la cuenta", como dice el propio ensayo. ${ }^{27}$ En todo caso, no he encontrado evidencia alguna de la relación de Winnall Dalton con Pancho Villa. Es más, Winnall no tuvo ningún her- 
mano Ilamado Garand (en verdad, éste es el nombre de una marca de rifles). Sí tuvo un hermano menor que se Ilamaba Frank, quien de hecho vivía en Guatemala, pero Frank Dalton aun vivía en Tucson a fines de 1917, mucho después de que supuestamente se habría refugiado en Centroamérica ante el temor de las represalias de Villa y por lo menos tres meses posteriores al establecimiento de su hermano Winnall en Honduras. ${ }^{28}$ En 1920, Frank todavía vivía en Tucson, según los datos del censo de los Estados Unidos de ese año. Cualquier involucramiento de Winnall Dalton con Pancho Villa debió haber sido contado por el propio Winnall a Roque Dalton para que éste tuviera conocimiento de ello, sin embargo ningún familiar de Winnall lo menciona en su abundante correspondencia o en entrevistas posteriores.

El relato de Pancho Villa puede tener un origen verídico en un caso muy notorio que involucró al sobrino de Winnall, Fred Ronstadt hijo, $y$ otras tres personas que fueron procesados por intento de llevar armas de contrabando a México en agosto de 1917. El cargamento en cuestión era bastante pequeño (dos pistolas y 750 unidades de municiones, descubiertos por un agente aduanero en Nogales, Arizona) y los procesados fueron liberados posteriormente por orden de un juez federal. No aparece en ninguno de los documentos legales del caso el nombre de Winnall, quien para ese entonces ya estaba viviendo en Honduras, pero el caso causó gran escándalo en Tucson y es muy posible que haya sido la pizca de verdad que originó la leyenda de su involucramiento con Pancho Villa, inclusive a través de un posible recuento embellecido por parte del propio Winnall a Roque. ${ }^{29}$

Todas estos elementos podrían llevarnos a pensar que la historia del engaño del padre de Roque Dalton a Pancho Villa es una exageración, si no pura invención. Sin embargo, Roque Dalton contó la historia en tantos medios distintos - en una novela, un ensayo y en una obra de teatro como veremos más adelante, y en conversaciones personales- y con detalles tan consistentes que uno se resiste a desestimarla por completo. En el ensayo previamente mencionado, Roque Dalton se refiere a unas "cartas íntimas" que su padre escribió sobre su viaje de México a Centroamérica. Yo no he podido encontrar dichas cartas ni tampoco otras referencias a ellas. Sin embargo, el tema más amplio del involucramiento de Winnall Dalton en la Revolución Mexicana amerita más investigación, sobre todo el papel que desempeñó en el ejército de Carranza.

También merece mayor estudio la posibilidad de que Winnall Dalton se quedara en Honduras y El Salvador para evitar el reclutamiento militar obligatorio en la Primera Guerra Mundial, lo cual queda 
sugerido por la tarjeta militar ya mencionada. Estados Unidos reimpuso el reclutamiento obligatorio en 1917 y, aunque Winnall ya estaba en Honduras para esas fechas, de haber regresado a casa hubiera sido sujeto del servicio militar. La posibilidad de que se quedó en Centroamérica para evitar ir a la guerra es, así, una hipótesis apoyada por el hecho de que regresó a Estados Unidos poco después del final de la guerra. Trabajó para la empresa bananera Cuyamel en Honduras y sufrió ahí una grave enfermedad, quizás la fiebre amarilla. Emigró a El Salvador, en donde se casó con Aída Ulloa Maín, de una familia acomodada salvadoreña, y de ahí partieron por barco a California. En el censo oficial de 1920 aparecen como casados y viviendo en San Francisco, pero no se quedaron por mucho tiempo allí. Para 1923, Winnall Dalton ya estaba de vuelta y bien establecido en El Salvador, como lo comprueba una carta a $L a$ Prensa en la cual ofreció \$3,000 al ganador de un concurso de acrobacias aéreas. ${ }^{30}$ Rico y socialmente prominente, él y su primera esposa tuvieron cinco hijos quienes llegaron a ser adultos.

Winnall Dalton compró su primer terreno en El Salvador alrededor de 1930 cerca de Colón, en el valle de Zapotitán al oeste de San Salvador. Empezó cultivando algodón y tuvo éxito desde el primer año, ampliando su producción después a azúcar y café. Se llevó bien con la oligarquía rural salvadoreña, sin embargo tuvo un espíritu de innovación y una flexibilidad propios de un capitalismo más moderno y dinámico aún poco común en su país adoptivo. En una finca de la cual había sido copropietario con un salvadoreño unos años antes, en la costa de Usulután, Dalton utilizó una avioneta importada desde Estados Unidos para rociar los cultivos con pesticida químico, supuestamente la primera vez que alguien hacía tal hazaña en El Salvador. ${ }^{31}$ Fue quizás este mismo avión el que donó en 1925 a la embrionaria fuerza aérea salvadoreña y el cual se estrelló al año siguiente, ocasionando la muerte de uno de los pioneros de la aviación nacional, Ricardo Aberle. ${ }^{32}$

Un empresario tan astuto como Winnall Dalton seguramente sabía que había comprado su terreno en una zona que vivía una tensión social cada día más intensa. El resentimiento de los campesinos que terminó explotando con La Matanza era ya ampliamente conocido y comentado en 1930, como lo han demostrado Jeffrey Gould y Aldo Lauria-Santiago, entre otros. ${ }^{33}$ Sus orígenes se remontaban a la eliminación paulatina del ejido, el fuerte deterioro de los salarios y las condiciones de vida para la clase obrera rural a partir de 1929, la represión violenta de la oposición política a lo largo de los años 20 y la simpatía por el comunismo utópico entre una parte de la población 
campesina. Gould y Lauria-Santiago han documentado la fusión de los conflictos étnicos, de clase y de género que agravaron el descontento entre la clase rural en los años anteriores a La Matanza, y presentan pruebas convincentes de que uno de los factores que exacerbaron la situación fue la explotación sexual de las mujeres indígenas y ladinas por parte de los terratenientes, una práctica que humilló y radicalizó a las familias campesinas. Varios de los militantes quienes dirigieron la sublevación de 1932 fueron productos de tales relaciones forzosas. ${ }^{34} \mathrm{En}$ enero de 1932, trabajadores armados con machetes, palos y algunas cuantas pistolas asaltaron puestos policiales, guarniciones del ejército y dependencias del gobierno en siete comunidades en el sudoeste de El Salvador, teniendo como resultado varias docenas de muertos. La reacción del dictador recién asumido Maximiliano Hernández Martínez fue rápida y despiadada. Sus tropas mataron a "miles y quizás decenas de miles de personas" en un lapso de tres semanas, aplastando así la rebelión y dejando una cicatriz profunda y permanente en el inconsciente colectivo del país. ${ }^{35}$

La represión de 1932 tuvo su epicentro a unos 30 kilómetros al oeste del terreno de Dalton, en el pueblo de Izalco. Un brote importante ocurrió también en Colón, a pocos kilómetros al este de su finca, y la violencia también llegó a las afueras de Santa Tecla, la ciudad rodeada de verdes y templadas colinas arriba del valle y el lugar donde Dalton tenía su familia oficial. El hijo de Dalton, quien tenía ocho años en ese entonces, recuerda como su papá convirtió a la finca en un virtual campo armado: "Él fortificó la finca. Yo no sé de dónde sacó todos esas armas de fuego, pero fortificó el lugar, y no tenía miedo" ${ }^{36}$ Con la represión todavía en marcha, Dalton salió de la finca y viajó hasta un cuartel cercano con la intención de recoger a "sus" trabajadores entre los centenares que habían sido detenidos en las redadas del ejército. Su hijo lo describió así: "Otros finqueros estaban ahí también, identificando a quienes sí conocían y quienes no... Entonces él revisó las filas y fue diciendo 'Éste es mío, éste, aquél'. Se llevó más o menos un centenar y los llevó a la finca y los puso a trabajar. Pero les advirtió, 'no pasen de ese cerco, porque si pasan, el ejército los va a agarrar o los va a matar'. El ejército tenía la autoridad de detener a cualquiera en la carretera". ${ }^{37}$

Es necesario puntualizar aquí que los recuerdos del hijo de Winnall Dalton sobre estos acontecimientos, aunque verosímiles y consistentes, no son de primera mano y serían difíciles de corroborar en forma independiente hoy en día. Éstos pertenecen al baúl de recuerdos que los descendientes de una familia se cuentan entre sí y a veces también a extraños. En ciertos momentos, como por ejemplo la 
relación de su padre con la madre de Roque Dalton, María García, los recuerdos de Winnall Dalton Ulloa efectivamente coinciden con los de otras fuentes. Asimismo, las memorias puede torcerse y embellecerse con el tiempo. Por lo tanto, un poco de escepticismo es recomendable al momento de considerarlas como parte de una documentación histórica formal.

Dado el compromiso crítico de Roque Dalton con los acontecimientos de 1932 a través de Miguel Mármol, es sorprendente que nunca exploró el papel de su propio padre en ellos. Dalton creyó que la clase social, y no la raza, fue la fuerza que impulsó el conflicto a lo largo de la historia salvadoreña. ${ }^{38}$ Teniendo en cuenta esa visión, uno podría pensar que la imagen de un hacendado rico pasando revista a una fila de campesinos atemorizados en un cuartel, sacando a los suyos como si fueran ganado perdido, mientras afuera miles más estaban siendo masacrados, habría capturado fuertemente la imaginación poética de Roque Dalton y su conciencia revolucionaria. Quizás no sabía del papel que jugó su padre. Pero Dalton definitivamente sabía que su padre tenía una finca grande en la región más afectada por La Matanza y, según su viuda, Aída Cañas, hasta estuvo de visita allí con su padre cuando el poeta ya era adulto. Dalton nunca menciona a su padre en el libro más célebre sobre la insurrección de 1932, Miguel Mármol, un brutal testimonio sobre la base de entrevistas extensas realizadas en Praga al organizador comunista y sobreviviente de La Matanza cuyo nombre es el título del libro.

Hombre inquieto y adaptable, Winnall Dalton había vivido probando distintos negocios y distintos países. Para mediados de los 30, su primera esposa, Aída Ulloa, había muerto y había mandado a sus cinco hijos a estudiar en los Estados Unidos. Ya con su segunda esposa, Winnall era un agricultor bastante próspero pese a la decaída económica en El Salvador. Compró terrenos adyacentes a su terreno original en Colón hasta juntar unas 3,500 manzanas en algunas de las zonas más fértiles del país. Le gustaban las apuestas, y su apodo era "Gana Todo" (una traducción de su nombre "Winnall" o "win all" al español) pero su amigos lo llamaban "Jack". "Aprendió el negocio", dijo su hijo. "Era muy rápido, era astuto, y tenía tan mal genio, que perdía los estribos con la rapidez de un chasquido de dedos. Y siempre andaba con una pistola. Sabía manejar la pistola".

Era vox populi que Winnall Dalton siempre portaba arma. Debió que haber tenido muchos enemigos y la gente realmente le tenía miedo a él y su temperamento violento, a tal punto que sólo en esta época de su vida adquiere algo de verdad la imagen de Roque Dalton como hijo de un pistolero. Algunos 
pueden encontrar hasta cierta justicia poética, una simetría histórica gratificante, en el hecho de que este hombre que siempre llevaba revólver bajo su cinturón engendró a alguien que también alzó un arma, pero en nombre de lo que él y otros consideraban la liberación del pueblo salvadoreño. Quizás es la continuidad de esa violencia lo que hace atractiva la imagen de un Roque Dalton como hijo de un bandolero violento.

Sin embargo, su relación con el poder de las armas fue radicalmente distinta. Roque Dalton era inútil con un arma, "era todo tatarata" con un rifle, como dijo un compañero de entrenamiento en Cuba. ${ }^{39}$ Como guerrillero armado, el poeta tuvo un papel menor y participó de una sola acción armada, que fue la toma de una radioemisora para la difusión de un manifiesto del ERP en marzo de 1974. Como escribió Gabriel Zaid, "esta impaciencia frente al interlocutor, esta glorificación de la pistola como la continuación del debate por otros medios" fue en verdad más característica de sus eventuales asesinos que del propio poeta. ${ }^{40}$

Esta historia no cambia el hecho de que Roque Dalton, la voz feroz de la revolución en América Latina, nació literalmente de la violencia de su padre. Una de las compras de tierra que realizó Winnall fue financiada en parte con un préstamo del Banco Occidental, propiedad de Benjamin Bloom, otro inmigrante del oeste de Estados Unidos a El Salvador. En algún momento, Dalton y Bloom riñeron tan violentamente sobre los términos del pago del préstamo, que uno de los guardaespaldas de Bloom le metió tres balazos a Dalton, quien sobrevivió el ataque y fue llevado a un hospital para su recuperación por varias semanas. Una de sus enfermeras fue María García Medrano, mujer humilde de unos 30 años, católica devota y empeñosa quien había financiado su propia capacitación médica y que las buenas familias salvadoreñas a veces contrataban para servicios de enfermería a domicilio. No estaba casada y quería tener un hijo, como dijo a sus amistades años después. Un día, el paciente americano se quitó las sábanas que cubrían su cuerpo lleno de cosidas heridas e hizo el amor con María García en su lecho en el hospital. El fruto de su encuentro furtivo (y a todas luces, consensual) fue Roque Dalton García, nacido el 14 de mayo de $1935 .{ }^{41}$

Hasta aquí, he analizado sólo obras de Roque Dalton relacionadas con la vida de su padre antes del nacimiento del poeta, o por lo menos como éste se la imaginó. Sin embargo, las obras más importantes de Dalton sobre el tema se refieren a las interacciones que él tuvo con su padre durante su juventud y a la paradoja de haber sido criado por una enfermera humilde como hijo de un extranjero rico. Roque Dalton vivió esta contradicción durante toda 
su vida - pobre, pero privilegiado; salvadoreño, pero mitad extranjero; comunista, pero hijo del más puro capitalismo- y la convirtió en el motor temático de su obra. Criado por su madre en un barrio de clase obrera de San Salvador, fue conocido como Roque García hasta los diecisiete años ya que, hasta esa edad, su padre se negó a reconocerlo. Su estatus como hijo de un terrateniente norteamericano era bien conocido en su barrio de talleres, cantinas y pequeñas fábricas. Winnall pasaba por la casa de su examante de vez en cuando a dejar un sobre de dinero para la educación del niño o mandaba a su chófer a dejar la plata. El ensayista y poeta David Escobar Galindo vivía en el mismo vecindario $y$, aunque unos años más joven que Dalton, recuerda el cotorreo del barrio sobre el papá rico del joven Roque y como este hecho hacía que los chicos del barrio le pidieran dinero. ${ }^{42}$ Winnall Dalton y María García intercambiaban durante estos años una gran cantidad de correspondencia, parte de ella aún está en el archivo de la familia Dalton en San Salvador. María lo presionaba y engatusaba para obtener más dinero para la educación del hijo, mientras Winnall contestaba con escuetas notitas con membrete del Casino Salvadoreño, rogándole ser paciente.

María García, la sacrificada enfermera, aparece en esta y otra correspondencia como absolutamente dedicada a su hijo. Es evidente que ella fue la única persona capaz de intimidar a Winnall Dalton, extrayéndole dinero para pagar la educación de su hijo natural durante toda su infancia y hasta los primeros años de su adultez. No tuvo más hijos de Winnall ni aparentemente ninguna otra relación romántica. La compañera inseparable de María García en esos años y durante casi toda la vida de Roque Dalton fue Fidelia Martínez, mujer de rasgos indígenas quien iba "llevando su cara de hombre con paciencia". ${ }^{43}$ Fidelia también fue madre soltera. Ella, María García y el joven Roque vivían en una casa alquilada que tenía una tienda y un bar y que estaba en la esquina muy transitada entre la $2^{\text {a }}$ Avenida Norte y la Calle 5 de noviembre. El pequeño negocio, incorporado a la casa, fue una combinación de tienda general y bebedero, un lugar donde los taxistas podrían tomar una bebida fría, las mujeres del barrio podrían actualizarse con los chismes y los hombres tomar una cerveza fría y hablar de fútbol. Fue allí en un barrio desaliñado a pocas cuadras de la catedral de San Salvador en donde Dalton empezó a desarrollar el tono urbano, irónico y franco de su mejor poesía y prosa.

En este barrio, el hijo adorado Roque Dalton fue uno de los muy pocos muchachos que pudo asistir a la escuela de la élite, el Externado San José, gracias al éxito que tuvo María en persuadir a Winnall Dalton para que pagara la colegiatura. La escuela tenía prohibida la 
entrada a hijos nacidos fuera del matrimonio, pero, según una historia familiar quizá apócrifa, María mandó a Winnall a platicar con los directores para convencerlos de hacer una excepción para este niño prometedor. Roque Dalton se refiere a este hecho incómodo de su juventud, es decir la dependencia económica cada vez más fuerte de su padre reacio, en un poema inédito que sería de mediados de los años 60, que dice en parte:

\author{
Bueno mi padre como \\ era un gringo iracundo, \\ Mister Dalton [...] \\ Yo esperándolo \\ saboreando a sorbetes \\ porque había que pagar la casa \\ el Colegio tan caro como \\ la enfermería (esta es mi mamá) \\ no podía dar para todo. ${ }^{44}$
}

Se graduó del Externado San José a fines de 1952, ya como Roque Dalton, y durante los próximos años desarrolló una relación correcta si no precisamente cálida con su padre, quien le ofreció enviarle a una universidad en los Estados Unidos. ${ }^{45}$ Cuando el recién graduado optó por estudiar Derecho en Chile, el padre igual se mostró de acuerdo con pagarle, pensando que el joven Roque recibiría una preparación conservadora y católica. Al contrario de esa expectativa, Dalton regresó de Chile a fines de 1953 con pensamientos socialistas que se endurecerían en un compromiso último con el marxismo revolucionario a lo largo de los años 50. Roque le presentó su joven esposa Aída Cañas a Winnall cuando se casaron en 1955 y Winnall les mandó regalos cuando nacieron sus hijos. ${ }^{46}$ La relación de padre e hijo se volvió más distante cuando Roque viajó a la Unión Soviética en 1957 para un congreso de juventudes comunistas, lo cual apareció en los diarios salvadoreños. Cuando Dalton fue arrestado por primera vez en 1959, el presidente militar de ese entonces, el coronel José María Lemus, dijo ante una conferencia de prensa que no haría nada para lograr la liberación del ahora famoso periodista y escritor, agregando con tono enfadado que "un universitario tiene suficiente discernimiento para distinguir el bien y el mal. Lo que pasa es que el compañero de ustedes es un niño consentido, tan consentido que se ha vuelto malcriado". ${ }^{47}$ Esta referencia obvia al padre de Dalton sugiere, primero, que su estatus de hijo de rico fue ampliamente conocido en El Salvador y, segundo, que a pesar de haber soportado el encarcelamiento por sus activida- 
des políticas, Dalton se encontraba en el extraño dilema de tener que probarse como disidente legítimo debido a su linaje, un linaje que su propio padre hasta pocos años antes ni siquiera había reconocido.

Inclusive así, Roque Dalton y su padre nunca cortaron del todo sus lazos. En su primer libro importante, La ventana en el rostro, publicado en 1961 en México, donde ya vivía, el poeta se refiere a su padre ausente con el tono resignado de alguien que poco o nada espera. El poema "La ducha" dice: "Mi padre, o un padre, en fin, sin posesivos/me enseñó a dominar furiosos potros. Las campesinas/me enseñaron a amar." $^{48} \mathrm{Su}$ padre puede haberle dejado una disposición a la violencia, dice Dalton, pero a la vez aprendió la lección fundamental de cómo amar de la gente común $y$, sobre todo, de las mujeres de su niñez y juventud. La ventana en el rostro fue uno de dos libros de Dalton publicados mientras vivía su padre. Envió una caja de ejemplares del libro a su madre con instrucciones de asegurarse de que Winnall recibiera uno. ${ }^{49}$ En efecto, algunos poemas en este libro parecieran haber sido dirigidos a Winnall, o por lo menos serían fáciles de entender por hombres impulsivos y de mal genio como él. En "La poesía", Dalton dice:

El hombre de los ojos iracundos preguntó: ¿Qué es la poesía?

El hombre de los ojos limpios

mirole profundamente, sin proferir palabra.

En su mirada había poesía. ${ }^{50}$

Dalton escarbó con más profundidad en las paradojas de su educación en Taberna y otros lugares, de 1969, el cual es de sus libros quizás el artísticamente mejor logrado. Se podría decir que Taberna es la declaración definitiva de Dalton como escritor, un libro tanto experimental como arraigado, lírico y suplicante a la vez, que demuele las fronteras tradicionales entre género y forma. Escrito principalmente en Praga, Taberna fue el primer libro de Dalton en tener un impacto verdaderamente internacional, al ganar el premio Casa de las Américas en 1969 y obtener críticas positivas en todo el continente latinoamericano. El diario El Nacional en Caracas lo calificó de "un libro que permite a la poesía latinoamericana cualquier posibilidad estilística o temática". Taberna, como ha señalado Luis Alvarenga en su estudio incisivo sobre la obra daltoniana, es un libro revolucionario tanto por su temática como por su experimentación radical con formas y estilos poéticos que fueron nuevos en la obra de Dalton y, en algunos casos, en toda la literatura salvadoreña. ${ }^{51}$ 
Una de las muchas obras referidas a Winnall Dalton en Taberna es el poema en prosa "La mañana que conocí a mi padre," que narra una de las visitas pasajeras de Winnall Dalton a la casa de María García para ver a su hijo y dejar fondos. Roque Dalton nos dice que tiene unos tres años y que su mamá no está presente porque la han Ilamado al hospital para ayudar en una neurocirugía de emergencia. Entonces, cuando llega el gran carro de Winnall a la casa, éste toca a la puerta y lo recibe la compañera Fidelia
Martínez, conocida como "la Pille", quien le pide al visitante que pase adelante y que perdone el desorden de la casa. La escena es cómica por lo incómodo del encuentro, que continúa con la Pille ofreciéndole un café, al lo cual Winnall casi ni responde. Ella levanta al niño Roque en sus brazos y se lo ofrece a Winnall para inspeccionarlo "como se hace con un pollo en venta o con un lechón." El padre lo besa y acaricia, rozando su cara barbada en la mejilla del niño. El texto reza:

Siento que el señor me pega una nalgada suave, me pasa una mano por el pelo, mi lindo pelo rubio de entonces que era la esperanza de mi mamá para que yo me distinguiera de por vida como un ser superior entre el conglomerado de murushos y jiludos cabellos salvadoreños; y, luego me quita el calcetín del pie derecho, desnudándomelo y tomándomelo entre la mano inmensa y fuerte y me lo aprieta pero sin hacerme daño, más bien siento unas cosquillas tibias que me dicen que el señor no es tan bravo como toda la gente grande que no sean mi mamá ni la Pille. [...] La Pille me coloca en el sofá y yo me quedo allí muy quieto haciendo cara hosca. El señor fuma como pensando y derrama la ceniza del cigarrillo en el suelo. Vuelve a acercárseme y me roza la cara con los dedos antes de dirigirse de nuevo hacia la calle. ${ }^{52}$

Al final del encuentro, el padre lacónico deja "un sobre blanquísimo" de dinero que la Pille agradece efusivamente hasta que, con constantes que-Dios-le-bendiga, se despide de él. Mientras oímos el carro de Winnall echarse a andar, la Pille se moja el dedo con saliva y empieza a contar el dinero.
En su superficie, este texto podría leerse como un estudio de dependencia y sumisión, visto en el extremo sometimiento de la mujer al visitante y su interés abyecto en el dinero que viene a dejar. Como afirman Gould y Lauria-Santiago, el vínculo de grandes automóviles con hacendados ricos y explo- 
tadores era muy profundo en la conciencia popular salvadoreña, un vínculo expresado además por el artista y escritor Salvador Salazar Arrué, o Salarrué, en su historia de La Matanza. La dependencia de El Salvador de los Estados Unidos, la sumisión forzosa de los pobres a los ricos y los efectos aplastantes del subdesarrollo en el alma humana fueron temas que le ocupaban mucho a Roque Dalton en esa etapa de su vida. En Pobrecito poeta que era yo, el narrador alter-ego de Dalton ataca a otros escritores salvadoreños, vivos y muertos, por lo que él considera su insuficiente atención al tema de clase, inclusive al popular poeta romántico Alfredo Espino, a quien el narrador critica por olvidarse de "los problemas nacionales, el drama real del pueblo, la miseria y la injusticia". ${ }^{53}$

Sin embargo, ver este complejo texto simple, o incluso mayormente, como una denuncia a la injusticia y a Winnall Dalton como un mero símbolo del imperialismo yanqui, sería injusto. Por el contrario, este pasaje expresa una verdadera ternura del padre ausente hacia su hijo prodigio y una sensación inequívoca de pena mientras acaricia su cara. Queda flotando en el aire, como el humo del cigarrillo de Winnall, una amarga conciencia de la brecha entre padre e hijo, un sentimiento de enajenación que deja al desnudo el profundo costo emocional de negar el parentesco, o aceptarlo sólo condicionalmente, tanto para el niño como para el padre.

La actitud del niño hacia el padre también es reveladora. Inclusive para un chico de tres años, parece extrañamente distante e indiferente ante la presencia de esta figura intimidante. Cuando la Pille le dice que bese a su padre, el niño se hace "el bobo" y decide quedarse ahí, "como un gusano de seda asustado por su primera ojeada al mundo". Se queda sentado, huraño, sobre el sofá y se niega a besar al visitante, como si estuviera esperando a que se fuera un intruso. El comportamiento del niño refleja el hecho de que el afecto del padre se expresa en los términos de este último. Aparece sin aviso previo, habla poco o sólo gruñe, y (aunque este hecho no aparece en el ensayo) le ha negado el apellido al hijo. Es innegable que Dalton expresa cierto cariño hacia su padre en este ensayo. Pero al combinar los temas del cambio revolucionario y su papel personal en ello y el tema de su padre en un mismo volumen, Dalton demuestra su rechazo al dinero y a las expectativas del padre. El rechazo a la autoridad reinaba en la expresión cultural a fines de los 60 en Europa y América, pero lo más importante de este pasaje es que da una muestra del resentimiento hacia el patriarca blanco que sentían los campesinos salvadoreños y en particular hacia los padres de hijos ilegítimos, lo cual contribuyó a La Matanza. ${ }^{54}$ Dalton, en efecto, toma 
ese sobre blanquísimo y se lo tira en la cara a Winnall.

Con su distante padre norteamericano, Dalton estaba plenamente consciente para 1969 de lo freudiano que parecía ante los demás su compromiso con el comunismo. Se lo dijeron a su cara. Las implicaciones freudianas tampoco han sido pasadas por alto por los escritores posteriores. ${ }^{55}$ Siempre sincero con sus lectores y consigo mismo, se refirió posteriormente a esta ironía en Taberna en un poema largo titulado "Los hongos" que en algún momento tenía la intención de publicar como libro aparte $y$ que, de hecho, no aparece en algunas ediciones de Taberna. En verso libre, expresa la desubicación emocional de ser hijo pobre de padre rico, producto de un barrio obrero y una educación elitista, rechazado por su padre pero a la vez subsidiado por él:

En el barrio de los golfos fui

el hijo del millonario norteamericano y en el Colegio

para los hijos de los millonarios [...] fui

el rapaz escapado por no sé qué puerta falsa del barrio de los golfos.

[...]

Mi alto nivel técnico en el fútbol

$y$ el hecho de ser hijo natural

me hicieron absolutamente señalable en el más gordo nivel social. "Dicen

que tú ingresaste al Partido Comunista por complejos" - me dijo

un día en México,

Miguelito Regalado Dueñas después de pagarme la cena y hablar del señor Marx.

Acto seguido, responde a esta auto-acusación, diciendo que se hizo comunista por puro despecho a su padre. Dirigiéndose a los miembros del jurado de Casa de Américas a quienes tenía previsto entregar el libro, afirma:

Los complejos, señores del Jurado, no tienen

nada que ver con la conciencia política: a lo más sirven para otorgar el matiz trágico. ${ }^{56}$

El retrato matizado y comprensivo que presentó Dalton de su padre en Taberna, así como la introspección honesta de sus propios motivos, apareció en forma casi simultánea con una descripción mucho menos halagadora de Winnall, también producida en Cuba. La obra de género indefinible "Dalton y Cía", de la cual hablé antes, tenía 
un título y tema parecidos a una obra de teatro a lo Bertold Brecht, y fue escrita y producida conjuntamente por Dalton y la dramaturga y poetisa de San Francisco, Nina Serrano, para la televisión cubana a fines de 1968. El título completo de esta pieza fue Dalton y Cía., donde se cuenta la vida y milagros, las aventuras económico-morales y las malandanzas de los nunca bien ponderados Hermanos Frank y Winnall Dalton en las hermosas (aunque inestables) tierras centroamericanas de Guatemala y El Salvador, pobladas como siempre de generales y mariposas. Serrano le dio otro título en inglés: The Daltons Ride South (Los Dalton Cabalgan Hacia el Sur). Serrano, casada con el sociólogo norteamericano Saul Landau, y Dalton se conocieron en Casa de las Américas en La Habana y decidieron colaborar en un proyecto que tenía el fin de avivar la monótona y chapucera televisión cubana de ese entonces. Dalton le mencionó que su padre fue un emigrado estadounidense con un pasado violento, y él y Serrano se pusieron de inmediato a trabajar en un guión en una suite del Havana Hilton durante varios días.

En la pieza que surgió de su colaboración, Winnall y Frank Dalton cabalgan por México en atuendo de vaquero, dos cazadores de fortunas que van estafando a todos a su paso, comenzando con Pancho Villa, para después casarse bien con "espeluznantes pero riquísimas jóvenes" de clase alta de la sociedad guatemalteca. ${ }^{57}$ El argumento, como escribió la crítica de teatro cubana Ileana Azor Hernández, "recurría al archivo familiar con el fin de descubrir entre bromas y risas un lance típico de la penetración norteamericana y el embrión de la oligarquía criolla" ${ }^{58} \mathrm{El}$ actor cómico Carlos Ruiz de la Tejera interpretó a Winnall. Serrano guarda tiernos recuerdos de esos días de trabajo con el encantador poeta, pese a los enconados conflictos que tuvieron durante la preparación del guión y los diez días de ensayos sobre su argumento. Serrano lo veía como una exploración satírica y humorística de la dinámica imperialista expresada a través de los hermanos Dalton, mientras Roque Dalton insistía en que se enfocara en la idea del subdesarrollo, sus efectos mentales y la forma en que éste deja tan vulnerables a la explotación a los países "hermosos pero inestables" mencionados en el título. Una censora o "asesora" enviada por el gobierno cubano estuvo presente durante todos los ensayos, advirtiéndoles a Serrano y a Dalton que debían eliminar ciertos diálogos o escenas por razones que sólo ella entendía. ${ }^{59}$

La pieza se presentó en vivo en la televisión cubana por una sola noche $y$, hasta donde recuerda Serrano, no fue grabada porque el equipo de grabación no funcionaba y nadie sabía arreglarlo. Entonces la única documentación que nos 
queda de este evento televisivo son unas fotografías, noticias de prensa y los recuerdos de las muchas personas que la vieron y quienes, casi unánimemente, la aclamaron. La obra tuvo un éxito rotundo, aunque efímero. Incluyó muestras de cine, audio, y música en vivo por Silvio Rodríguez y Noel Nicola, una experiencia teatral multimedia que, en 1968, estaría a la vanguardia en casi cualquier parte del mundo y que para la televisión cubana fue totalmente revolucionaria. El escritor Pablo Armando Fernández llamó a Serrano esa misma noche para decirle que su obra había sido "la liberación de la televisión cubana" y hasta Fidel Castro mandó un recado diciendo que le había gustado luego de que Dalton le había pedido personalmente que la viera.

La obra de teatro Dalton y Cía. fue probablemente el origen del mito perdurable de la ascendencia de Roque Dalton de vaqueros del Oeste. Escritores posteriores tomaron como verídica una sátira graciosa digna de Brecht. Serrano recuerda que, en su primera conversación con Dalton, le preguntó si acaso era pariente de los famosos hermanos Dalton de Kansas. Dalton le contestó afirmativamente y Serrano cree que así fue como nació el mito de que Roque Dalton era hijo de bandidos fronterizos. ${ }^{60}$ Sin embargo, Dalton puede haber tenido otros motivos. Los sentimientos del poeta hacia su padre y su familia "oficial", nunca precisamente cá- lidos, se volvieron especialmente amargos en 1968 debido al fracaso de Dalton en obtener una parte de los bienes de Winnall luego de su muerte en 1962. Con la ayuda de María García, quien se quedó en El Salvador mientras Roque vivía en Checoslovaquia con su esposa y sus tres hijos, Dalton había contratado un abogado para luchar por su derecho legítimo a una porción de la considerable riqueza de Winnall. El hecho de que no tuvo éxito dejó una secuela de resentimiento entre los dos linajes de Winnall que persistió hasta hace muy poco tiempo.

Claro que muy pocos de los televidentes cubanos esa noche de 1968 habrían conocido esta historia personal. Sólo vieron a un dramaturgo salvadoreño ridiculizando a su padre difunto como la personificación de una doctrina odiada. Teniendo en cuenta este contexto, Taberna, publicado pocos meses después, le dio una oportunidad a Dalton de ofrecer una descripción más refinada de la vida y personalidad de Winnall y de sus propios sentimientos hacia él, tanto para el público cubano como para él mismo.

Roque Dalton lidiaba con el legajo de privilegios y penas dejado por su padre casi hasta el final de su vida. Fue criado casi exclusivamente por su madre, pero, a diferencia del padre, ésta aparece en muy pocas ocasiones en su voluminosa obra. Tampoco se asoman mucho la mujer y los hijos de Dalton, en 
comparación con el padre y con el vasto círculo de amigos, amantes y colegas quienes pueblan sus libros. Parecería que Dalton mantuvo su círculo familiar más íntimo fuera de su obra y que su padre nunca fue parte de ese círculo. En la historia de Dalton y Cía. de 1973, se refiere al vacío de memoria causado por la negativa de su padre de reconocerlo públicamente cuando era niño y por los valores hipócritas de la sociedad salvadoreña que permitía, y hasta obligaba, a semejante crueldad. Con un tono herido, Dalton alude al hecho de que la historia de su padre le había sido ocultada:

Mis distanciadas relaciones con él, además de su carácter poco comunicativo (hablo del carácter que ejercitaba frente a sus incontables hijos naturales y no el que supongo ostentaba frente a esas gráciles muchachas con cara de venado que le acompañaron hasta la muerte), hicieron que yo ignorara todo acerca de los padres de mi padre. ${ }^{61}$

Más tarde en el mismo texto, especula sobre sus propios motivos al escribir tanto sobre su padre y los tíos a quienes nunca conoció y se pregunta si al contar la historia de ellos pone en duda, de alguna forma, su propio compromiso con el comunismo. Sugiere que una imagen falsa de su padre, y por lo tanto de él mismo, había comenzado a arrai- garse en la mente del público (como de hecho había ocurrido) y que, algún día, un grupo de historiadores tendrían que rectificar esta distorsión. La tarea de separar el mito de realidad implicaría ir más allá de los recursos de un pobre poeta, aunque él idealmente orientaría al equipo de investigación. Se pregunta:

\begin{abstract}
¿Por qué un comunista toma una actitud tan liberal contra las evidentes canalladas de sus progenitores? En primer lugar, un poco más de respeto porque el respeto es la mitad de la vida. En segundo lugar, un poco más de seriedad y de rigor histórico, exigible en la actualidad (1973) aun en el caso de los más simples, e incluso de los renuentes, espectadores de la historia. No me vengan a pedir que haga de mi padre y mi tío dos Robin Hood americanos porque la verdad es que no lo fueron. Y aun más: fueron precisamente lo contrario, como correspondió a los pioneros del capitalismo en cualquier parte del mundo. ${ }^{62}$
\end{abstract}

Sin embargo, en su esencia, este dilema es suyo y no de su padre. En un momento en que estaba literalmente transformando 
su persona, a punto de tomar un nombre nuevo y de someterse a una ligera cirugía plástica para poder unirse a un grupo guerrillero en San Salvador sin ser reconocido, Dalton se preguntaba sobre cómo los misterios del pasado de su padre se habían vuelto los suyos propios. Pasaría a ser una persona nueva. Julio Delfos Marín fue el seudónimo que adoptó durante su desastrosa pasan- tía con el Ejército Revolucionario del Pueblo. Escribiendo casi en la víspera de su partida a la lucha armada, expresa una sensación de estar desligado de su propia personalidad. Al escribir sobre su padre y sus tíos, inclusive en maneras que él sabía que no eran estrictamente ciertas, se estaba recordando de quién era y de dónde venía. Con su introspección característica, escribe:

El clima que me interesaría crear aquí para mi padre y mi tío, no [es] para refocilarme en las tradicionales y melosas aguas del homenaje familiar burgués [...] sino para lanzar a mis muertos la flechita poética, repito, del puro acto de amor. De un acto de amor, por otra parte, que contribuya a aclararme el espejo que interrogo con desesperación en los amaneceres, como diría Daphne du Maurier: ¿Soy acaso lo que parezco? ¿Tengo derecho a ser lo que soy? ¿Dónde nacieron, crecieron, quedaron, las raíces de este rostro feo, de esta caricatura de espadachín sinvergüenza que pagó ayer por la tarde sus impuestos? ${ }^{23}$

Dalton nunca tuvo la oportunidad de contestarse adecuadamente estas preguntas. Murió luego de dos años de habérselas formulado. Su identidad ya había sido tan "ficcionalizada", para usar el término de Lara Martínez, ${ }^{64}$ por lo que él mismo ya se preguntaba quién en realidad era el Roque Dalton, como se puede ver en el pasaje anterior. Dalton borró aún más su persona pública con su último libro, conocido popularmente como Poemas clandestinos y escrito en las catacumbas de la vida clandestina en 1974 bajo cinco seudónimos y publicado póstumamente. ${ }^{65} \mathrm{El}$ reencuentro con la familia de su padre en Tucson finalmente ocurrió, casi 30 años después, cuando su hijo Juan José, periodista salvadoreño, viajó a Tucson y fue recibido cálidamente por los descendientes de Winnall Dalton, entre ellos la nieta de Fred Ronstadt y sobrina segunda de Roque Dalton, la cantante Linda Ronstadt, quien le regaló a Juan José un retrato de cerca de 1900 de Winnall Dalton padre, abuelo del poeta. Aunque no vivió lo suficiente para aprender la verdadera historia de su parentela, Roque Dalton al final de su existencia ya se comenzaba a hacer las preguntas correctas. Son las generaciones posteriores a las que les ha tocado el trabajo de comenzar a contestarlas. 
1 Lara Martínez, R. La tormenta entre las manos, Concultura, San Salvador, 2000. 60

2 Alvarenga, L. El ciervo perseguido, Concultura, San Salvador, 2002. 85

3 Huezo Mixco, M. "'Cuando salí de La Habana..." Cultura 89, 2005. 94

4 Hernández-Aguirre, M. "La nueva poesía salvadoreña: 'La generación comprometida”'. Cultura 20, 1961. 77-99

5 Vásquez Olivera, M. "País mío no existes': Apuntes sobre Roque Dalton y la historiografía contemporánea de El Salvador". Istmo 11, 2005

6 Alas, J. Roque Dalton: el turno del poeta, Editorial Delgado, San Salvador. 1999; Arias Gómez, J. En memoria de Roque Dalton, Editorial Memoria, San Salvador. 1999; Armijo, R., "La historia de otra gran injusticia", en Recopilación de textos sobre Roque Dalton, ed. Héctor García Verzi. Ediciones Casa de las Américas, La Habana, 1986. 112. El poeta Armijo, amigo íntimo de Dalton, se refiere a "sus conflictos personales al reaccionar vivamente contra las petrificaciones del proceso revolucionario".

7 Cortazar, J. "Una muerte monstruosa", en García Verzi, op cit. 556

8 Galeano, E. Días y noches de amor y de guerra, Editorial Alianza, México, 1986. 149

9 Solís, A. Roque Dalton: un disparo a la izquierda del corazón, Editorial Universidad Francisco Gavidia, San Salvador, 2005. 14-15

10 "Henry Dalton. From a book of original letters by Winnall Agustín Dalton of Tucson, Arizona..." documento inédito, Ronstadt Family Papers, University of Arizona Library Special
Collections (en adelante RFP-UA), caja

2 carpeta "Family Histories"

11 Una historia familiar escrita por su nieto Roger Dalton, publicado en el periódico Arusa Herald en octubre de 1937 y reescrito por Lupe Dalton Ronstadt, tía del poeta Roque Dalton. RFP-UA, caja 2.

12 "F. Ronstadt, Autbio.," documento inédito, RFP-UA, Box 2

13 "Henry Dalton”, op. Cit.

14 Sherman, J., y Ronstadt, E. "Wagon Making in Southern Arizona", Smoke Signal 31, 1975. 1-20

15 Ronstadt, F. Borderman. University of Arizona Press, Tucson, 2003. 78. Este libro es una distilación del documento inédito "F. Ronstadt, Autobio," op. Cit., que data de más o menos 1940.

16 Sheridan, T. Los tucsonenses, University of Arizona Press, Tucson, 1986. 99

17 Ibid., 100

18 Sherman y Ronstadt, op. Cit.

19 Papeles de la Familia Ronstadt, Sociedad Histórica de Arizona, Tucson (en adelante RFP-AHS), Caja 2, Carpeta 17

20 Arizona State Board of Health, Bureau of Vital Statistics, 31 de agosto de 1917

21 Vea correspondencia entre Dalton y el historiador CC Baker de San Pedro, California, a quien Dalton contrató para escribir una historia de la vida y las batallas legales de Henry Dalton. Winnall Dalton padre murió antes de la terminación del proyecto. RFP-AHS, Caja 2, Carpeta 13, "Henry Dalton."

22 Tucson City Directory (1912), Biblioteca del Estado de Arizona, Archivos y Documentos Públicos, Phoenix 
23 Entrevista con Winnall Dalton Ulloa, San Salvador, 9 de enero de 2007

24 Ibid

25 Dalton, R. Pobrecito poeta que era yo..., San Salvador, UCA Editores, 1994. 115

26 Dalton, R., "Un fragmento de Dalton y Cía.", Cultura 89 (2005). 31

27 Ibid. 29

28 Arizona Daily Star, "Mortuary: Winnall A. Dalton", 1 de septiembre de 1917. El obituario da la nómina de los siete hijos sobrevivientes de Winnall, entre ellos Frank y Lupe Dalton (la esposa de Fred Ronstadt), ambos con residencia en Tucson, y "W.A. Dalton Jr., of Honduras, Central America.", según indica el periódico.

29 Corte del Distrito de los Estados Unidos, Distrito de Arizona, caso United States versus Enrique Leiva et al, orden de captura, 27 de agosto de 1917, Archivos Nacionales, Región Pacífica, Grupo de Control 21, Distrito de Arizona, División Tucson, Carpeta 557, Caja 2. Véase también una carta de Fred Ronstadt que recuenta el caso a la revista Arizona Agriculturalist, con fecha 16 de abril de 1925. RFP-AHS, Caja 2, Carpeta 15

30 Cornejo, Douglas Alcides. La aviación nacional: Historia de la Fuerza Aérea Salvadoreña. San Salvador, Concultura, 2002

31 Entrevista con Winnall Dalton Ulloa, 17 de enero de 2006

32 Ibid.

33 Gould, J. y Lauria-Santiago, Aldo. To Rise in Darkness: Revolution, Repression and Memory in El Salvador, 1920-1932. Durham, Carolina del Norte, Duke University Press, 2008
34 Ibid.

35 Lindo-Fuentes, H.; Ching, E., y Lara Martínez, R., Remembering a Massacre in El Salvador: The Insurrection of 1932, Roque Dalton and the Politics of Historical Memory, Albuquerque, University of New Mexico Press, 2007. 23

36 Entrevista con Winnall Dalton Ulloa, 2006, op. Cit.

37 Ibid.

38 Lindo-Fuentes et al, op. Cit.

39 Alvarenga. Op cit.

40 Zaid, G., "Enemy Colleagues: A Reading of the Salvadoran Tragedy", Dissent 29. 13-40.

41 La información en este párrafo está basada en entrevistas con Winnall Dalton Ulloa, op. Cit.; Juan José Dalton, San Salvador, 11 de noviembre de 2005, y Aída Cañas, San Salvador, 5 de enero de 2006, y La Habana, 9 de agosto de 2006.

42 Entrevista con David Escobar Galindo, San Salvador, 2004.

43 Dalton, R., Taberna y otros lugares. La Habana, Casa de las Américas, 1969. 87

44 Dalton, R., fragmento poético sin título, "A lo que íbamos...", Archivo Roque Dalton, caja sin número, Museo de la Palabra y la Imagen, San Salvador

45 Entrevista con Aída Cañas, 2006, op. Cit.

46 Ibid.

47 Lemus, J., citado en El Diario de Hoy, 24 de diciembre de 1959

48 Dalton, R., No pronuncies mi nombre: poesía completa I, San Salvador, Concultura, 2005. 241 
49 Dalton, R., a María García, 8 de marzo de 1962, Archivo de la Familia Dalton, San Salvador. Dalton escribe: "El libro mío, aquel empastado para mi papá [...] hágaselo llegar Ud. a mi papá”. Lo que no está claro con esta carta y su fecha es si Dalton se refería a La ventana en el rostro o su segundo libro, El turno del ofendido, publicado en Cuba a comienzos de 1962. De todos modos, es casi seguro que el libro llegó tarde, pues Winnall Dalton murió el 24 de marzo de ese año.

50 Dalton, R., No pronuncies mi nombre: poesía completa I, op. Cit. 244

51 Alvarenga, L., op. Cit.

52 Dalton, R., Taberna, op. Cit. 88

53 Dalton, R., Pobrecito poeta..., op. Cit. 201.

54 Gould y Lauria-Santiago, op. Cit.

55 Lara Martínez, R., "Nota introductoria: en las manos un pequeño país". En No pronuncies mi nombre: poesía completa I, San Salvador, Concultura, 2005
56 Dalton, R., No pronuncies mi nombre: poesía completa II, San Salvador, Concultura, 2008

57 Azor Hernández, I., "Diálogo incluso sobre el teatro de Roque Dalton", en Recopilación de textos, op. Cit.. 402

58 Ibid. 401

59 Entrevista a Nina Serrano, Oakland, California, 27 de septiembre de 2006

60 Ibid.

61 Dalton, R., "Fragmento de Dalton y Cia.", op. Cit. 28

62 Ibid., 39

63 Ibid.

64 Lara Martínez, R., La tormenta entre las manos, op. Cit. 60

65 Dalton, R., No pronuncies mi nombre: poesía completa III, San Salvador, Concultura, 2008 